\title{
«Es la vida lo que tiene que ser una obra de arte» Transposición filmoliteraria de Naturaleza muerta con cachimba y Cachimba*
}

Fecha de recepción: 04 de abril de 2021

Fecha de aprobación: 22 de mayo de 2021

\section{Resumen}

Este artículo tiene como objetivo la comparación de la novela Naturaleza muerta con cachimba (1990) de Donoso y su correspondiente traslación filmoliteraria Cachimba (2004) de Caiozzi. Este cotejo se presenta a partir de la propuesta de Sánchez Noriega con base en las añadiduras, cambios de personajes y al orden narrativo/filmico. Para desarrollar este planteamiento es preciso analizar a Marcos Ruiz y a Larco en relación con el arte. Así, se reconoce la importancia de la estructura temporal para comprender la «metamorfosis existencial» (Cid Hidalgo, 2019) del protagonista la cual nos permite reflexionar sobre el planteamiento de que Marcos es un reflejo invertido de Larco. A través de lo anterior se devela la falsedad del mundo del arte, que tanto la novela como el film presentan con humor, y de qué manera Marcos es un reflejo especular de Larco que, paradójicamente, encuentra su verdadero «yo» al metamorfosearse en el artista gracias al poder de la cachimba.

Palabras claves: cachimba, espejo, humor, Larco, Marcos.

Citar: Pinto, Francisca. "Es la vida lo que tiene que ser una obra de arte Transposición filmoliteraria de Naturaleza muerta con cachimba y Cachimba". La Palabra, (40), e12633. 3ihttps://doi.org/10.19053/01218530. $\underline{\mathrm{n} 40.2021 .12633}$

\section{Francisca Pinto Inzunza}

Estudiante de doctorado en

Literatura Latinoamericana.

Universidad de Concepción.

Chile

fran.pintoinzunza@gmail.com

(iDhttps://orcid.org/0000-0002-

$\underline{7417-3583}$

* Artículo de reflexión.

Este trabajo forma parte del proyecto de tesis doctoral financiada por ANID. 


\section{"It is the life that has to be a work of art" Film-literary transposition of Naturaleza}

\section{muerta con cachimba and Cachimba}

\section{Abstract}

The purpose of this paper is to compare the novel Naturaleza muerta con cachimba (1990) by Donoso and its corresponding filmoliterary translation Cachimba (2004) by Caiozzi. This comparison is presented based on Sánchez Noriega's proposal founded on the additions, changes of characters, and the narrative/film order. To develop this approach, it is necessary to analyze Marcos Ruiz and Larco concerning the art. Thus, the importance of the temporal structure is recognized to understand the «existential metamorphosis» (Cid Hidalgo, 2019) of the protagonist, which allows us to reflect on the proposition that Marcos is an inverted reflection of Larco. Through the above, the falsity of the art world is revealed, which both the novel and the film present with humor, and how Marcos is a mirror reflection of Larco who, paradoxically, finds his true «I» when he metamorphoses into the artist thanks to the power of the pipe.

Keywords: pipe, mirror, humor, Larco, Marcos.

\section{"É a vida que tem que ser uma obra de arte" Transposição filme-literária de Naturaleza muerta con cachimba e Cachimba}

\section{Resumo}

Este artigo visa comparar o romance Naturaleza muerta con cachimba (1990) de Donoso e sua correspondente tradução cinema-literária Cachimba (2004) de Caiozzi. Esta comparação é apresentada a partir da proposta de Sánchez Noriega com base nas adições, mudanças de personagens e na ordem narrativa/filmônica. A fim de desenvolver esta abordagem, é necessário analisar Marcos Ruiz e Larco em relação à arte. Assim, é reconhecida a importância da estrutura temporal para compreender a «metamorfose existencial» (Cid Hidalgo, 2019) do protagonista, o que nos permite refletir sobre a proposta de que Marcos é um reflexo invertido de Larco. Através do exposto, é revelada a falsidade do mundo da arte, que tanto o romance quanto o filme apresentam com humor, e como Marcos é um espelho reflexo de Larco que, paradoxalmente, encontra seu verdadeiro «eu» metamorfoseando-se no artista graças ao poder da cachimbo.

Palavras-chave: cachimbo, espelho, humor, Larco, Marcos. 
El estudio de la traslación de textos literarios al cine contempla la vinculación de dos formas de narrar: la narración literaria y la narración cinematográfica, es decir, la transposición. Nos encontramos frente a una forma de mimesis, en la que prevalece la ficción, esto es, contar historias. El cine ha encontrado el medio natural para contar historias de la literatura, ya que esta se presenta como una exquisita fuente de ficción. El cambio fundamental surge desde el medio de cómo se narra, pues la literatura cuenta historias y el cine construye ficciones.

El discurso literario se funda en la palabra y genera un mensaje por medio de signos lingüísticos que se entregan al receptor, el cual debe decodificar para luego comprender el mensaje, y así sucesivamente, con el fin de generar la creación imaginaria del mundo. Por ello, el lector juega un papel preponderante, pues su experiencia es totalmente única. De acuerdo con sus conocimientos y experiencia, el lector podrá completar lo que Wolfgang Iser (176) denomina «espacios vacíos», generando la relación dialéctica entre el plano textual y la lectura. Por otro lado, el discurso cinematográfico ocupa, como medio, una serie de imágenes en movimiento que imitan segmentos de realidad; es una mirada cargada de palabras. Ergo, siguiendo a Iser (176 y ss), en el cine el objeto está frente a la mirada, caso contrario a la literatura, en la cual nos encontramos inmersos en la lectura.

Las propiedades y potencialidades que posee cada medio son lo que puede construir la historia de acuerdo con sus determinadas características. Debido a ello, no se pueden trasladar directamente todos los elementos de la literatura, a pesar de compartir el código del relato, pues la finalidad es recrear alguna dimensión del discurso literario base. Así, el cine se posiciona como un dialogante de la literatura y no una degradación de la misma.

Para abordar el análisis de Naturaleza muerta con Cachimba y Cachimba es necesario precisar que en adelante se optará por el término «transposición» (Wolf 15 y ss), «trasvase» (Sánchez Noriega 23 y ss) o traslación por sobre «adaptación». Esto, debido a que dicho término resulta problemático en tanto que podría suponer una jerarquía, en la que el cine estaría sub- yugado a la literatura. Lo mismo sucede con «fidelidad»: el cine no pretende hacer la réplica «perfecta» del discurso literario, sino que se constata como un objeto estético autónomo.

En el estudio de las traslaciones filmoliterarias se deben considerar ciertos elementos que condicionan el resultado de este proceso. Un elemento significativo es la intertextualidad referida al «intercambio dialógico cultural que trasciende el fenómeno literario» (Rebolledo 14). Este elemento es la base del estudio comparatista, debido a que, en un film una serie de discursos se entremezclan, todos ellos relacionados con el circuito interno del cine. En este sentido, se privilegiará el análisis comparatista entre la nouvelle y el filme, considerando, por ejemplo, ambos títulos.

Otro rasgo es el autor, Rebolledo lo define, siguiendo a Umberto Eco, como «una estrategia textual que se configura en el discurso mismo como la conciencia estructurante de éste y como una hipótesis interpretativa para el lector» (14). Así el concepto de autor en un filme no exige a una figura concreta en particular, sino al constructo que se genera, producto del trabajo en con- 
junto del director (realizador), el productor, el guionista, entre otros; puesto que lo significativo es la intención que se desprende del resultado final. En nuestro caso particular, es particular, es interesante la relación entre el escritor José Donoso y el cineasta Silvio Caiozzi , quien ha logrado permear en sus películas el espíritu donosiano, producto de su ávida lectura del autor chileno.

Además de lo mencionado, es importante considerar de qué manera la traslación: interpreta, imagina, recorta, mueve y agrega. El visionado del receptor permitirá estudiar estos cambios y cómo se enriquecen (o empobrecen) en el nuevo discurso. Al enfrentarse a un cambio de vehículo sígnico es vital preguntarse qué sucede con el sentido de lo transmitido.

Estamos frente a un juego de experiencias, condensaciones y desplazamientos que exige al menos una franja de independencia, que podrá ensancharse o estrecharse según el criterio elegido. Así, estudiar la transposición es siempre lectura sobre lectura.

Ya estipulados los elementos básicos y transversales para el análisis de un trasvase de la literatura al cine, se analizará la novela Naturaleza muerta con cachimba de José Donoso (1990) y su versión fílmica titulada Cachimba ${ }^{l}$ (2004) de Silvio Caiozzi, traslación única hasta esta fecha.

A partir de ello, se sostiene que Marcos Ruiz Gallardo se constituye como un reflejo especular del pintor Larco. Si bien en ambos discursos los hechos y los personajes presentan distintos matices, es posible intuir que a través de la narración ulterior presenciamos la «metamorfosis existencial» (Cid Hidalgo 231) de Marcos que lo lleva a radicarse de forma definitiva en Cartagena y vivir a partir del arte de Larco.

El objetivo de esta lectura es reflexionar acerca de qué manera Marcos es un doble invertido del pintor Larco. Para desarrollar este planteamiento es necesario, en primer lugar, reconocer la importancia de la estructura temporal para comprender su «metamorfosis existencial». En segundo lugar, se analizará al personaje Marcos Ruiz y a Larco en relación con el arte. En tercer lugar, se analizará a Hilda y Marcel, personajes que han sufrido modificaciones respecto del texto matricial. Finalmente, se hará una breve alusión en torno al humor.

Para desarrollar esta lectura comparatista se utilizarán los conceptos de orden, supresiones, sustituciones y añadidos que trabaja Sánchez Noriega (97) siguiendo los postulados de Gerard Genette. Si bien estos conceptos son bastante estructurales, son indicios desde los cuales se ha podido establecer la hipótesis, pues posibilitan y tensionan el análisis comparatista con miras a interrogar sobre el sentido de lo transmitido en ambos objetos estéticos.

\section{Cuestiones preliminares}

Como menciona Giuseppe Gatti Riccardi (30), la relación de amistad entre Donoso y Caiozzi fue fundamental. Al cineasta siempre le atrajo la literatura donosiana y cuando el

Filme de 142 minutos, grabada en película de $35 \mathrm{~mm}$ a color. 
escritor vio su trabajo, le surgió la idea de crear juntos, obsesionados por desarrollar las ideas que tenían en mente. Caiozzi relata que Donoso había pensado en llevar esta Naturaleza muerta con cachimba al cine, pero falleció antes de que pudieran comenzar a trabajar (Fernández s/p.). Biénzobas ( $\mathrm{s} / \mathrm{p}$ ) rescata la estrecha relación del autor con el séptimo arte y de qué manera las novelas del autor han sido de enorme interés para trasladarlas al cine. De hecho, su elocuencia para narrar hizo que el propio Michelangelo Antonioni quisiese trabajar con él.

Cachimba y su relación con la nouvelle fue el punto de partida de Gatti Riccardi para estudiar las isotopías o puntos de confluencia en ambas obras. En dicho artículo, menciona las temáticas donosianas presentes y luego se centra en las isotopías como los espacios de Santiago, Cartagena, la casa-museo, la relación entre el pasado y el presente, y los personajes de Marcos, Felipe e Hilda. La lectura de Gatti Riccardi concluye, entre otras cosas, que el espacio cerrado explica la caracterización y el actuar de los personajes: «Asimismo, se repite en los textos literarios y fílmicos la representación de una trama ubicada en un espacio cerrado, decadente y claustrofóbico [...]» (46).

Centrado en la nouvelle de Donoso y direccionando su mirada sobre la dimensión museal y la figura del curador, Juan Cid Hidalgo (234) propone que Marcos experimenta una «metamorfosis existencial» (231), producto de su acercamiento al pintor Larco que lo llevarán, finalmente, a un conocimiento falaz del arte:

Dueño de los lienzos, transformado en curador e inclusive en restaurador de las obras monocromas en azul (156 y ss.), empoderado en los roles heredados, justifica su menesterosa vida a partir de la negativa a vender la obra del artista [...]; a la vez que ejercita su egoísmo y desconfianza en el público de las artes (246).

Además de lo ya mencionado, es relevante indicar la preocupación estética de Donoso por la pintura, la cual podemos apreciar, por ejemplo, en Átomo verde número cinco (1973), donde los protagonistas son Roberto Ferrer, quien es un odontólogo aficionado a la pintura, y Marta Mora, su esposa.

Roberto Ferrer, en los momentos que le dejaba libre la práctica de la odontología, se dedicaba a la pintura - unas abstracciones de lo más elegantes en negro y blanco sobre arpillera rugosa, centradas alrededor de unos cuantos átomos en un color fuera de paleta-, y aunque no poseía una educación artística formal, ciertamente «tenía mucho museo», como solía decirle Paolo, que los asesoró en la decoración del piso (Donoso 2).

Ellos llevan quince años de matrimonio y comienzan a experimentar una serie de pérdidas de objetos en el nuevo departamento que habitan. La primera de ellas fue la desaparición de la mejor pintura hecha por Roberto: «Átomo verde número cinco», luego de ella vendrán un candelabro, un pisapapeles, unas litografías, la falange del meñique de Marta hasta objetos tan anodinos como una bombilla y una linterna. Los personajes permanecen como espectadores ante la ausencia/hurto de los enseres hasta que se deciden por recuperar la obra creada por Roberto, embarcándose en una búsqueda que demostrará su alienación y que los 
conducirá por espacios degradados. En el caso de esta nouvelle, los protagonistas comienzan una persecución delirante de un cuadro; en el caso de Naturaleza muerta con cachimba será la indagación y apropiación del universo del pintor Larco.

Señalado lo anterior procederemos al análisis tomando como base las reflexiones y lecturas anteriores.

\section{La narración ulterior}

Quisiera comenzar este análisis con la imagen fílmica de Marcos Ruiz Gallardo en un microbús santiaguino. El tiempo transcurre sin cesar, se puede apreciar el cambio de estaciones del año, no así el talante sombrío de nuestro héroe. Acto seguido, una voz en over transmite parte del inicio de la nouvelle hasta detenerse en la escena en la que el protagonista deshoja el libro de actas de la «Corporación Para la Defensa del Patrimonio Artístico Nacional»» e intenta arrojar sus hojas por las aguas inmundas del río Mapocho, pero estas se vuelan.

Tanto en la novela como en el filme, Marcos es un personaje con una vida anodina, un perdedor, atormentado por no poder concretar sus pulsiones sexuales con su contenida novia Hildita. Esto cambiará una vez que el héroe se encuentra frente al cuadro «Naturaleza muerta con cachimba» de Larco; el efecto es crucial, al punto de experimentar el síndrome de Stendhal (Cid Hidalgo 235), desde este momento, sus motivaciones se limitarán al universo del enigmático artista.

Tanto la novela como el filme presentan un narrador ulterior y mantienen la analepsis. Este asunto de orden (Sánchez Noriega 100) posibilita refrendar la «metamorfosis existencial» del personaje como también su ardid para abandonar la ciudad. No obstante, el orden resulta un recurso que adquiere distintos ribetes: en la nouvelle, el narrador nos dice haberse sentido «profundamente deprimido» (Donoso 99), luego de la disolución de la CPLDDPAN; pista falsa para el lector, ya que solo al final del texto se dará cuenta de que esto fue una estratagema del protagonista con el fin poder radicarse en la casa de Larco sin levantar sospechas.

La película, en tanto, sí nos muestra al héroe deprimido que acaba en la tanguería de Marcel, intentando superar la desazón que le produjo Felipe al pintar de «azul paquete de vela» las obras de Larco. Solo después se dará cuenta del puente que le ha construido el anciano para que pueda preservar la obra de Larco.

Este cambio es capital al pensar que en la nouvelle Larco transmuta en Felipe; no así en la película, puesto que se deja esta interrogante abierta. En ambos casos, es necesaria la analepsis para explicar el aprendizaje del personaje, quien pasa de una vida absolutamente anónima a refugiarse en una vida de artista.

En adelante CPLDDPAN. 


\section{Marco(s)/ Larco}

La relación entre Ruiz Gallardo y el pintor es evidentemente decidora. Antes de explicitar algunas ideas que resultan interesantes es preciso caracterizar a ambos personajes.

A diferencia del protagonista fílmico, el Marcos literario es menor, tiene 31 años, además, psicológicamente son distintos. El héroe novelesco se revela desenfadado en sus pensamientos, pero más mesurado en sus acciones, por ejemplo, al explicarle a Hildita la actitud de la senecta de CPLDDPAN, piensa de ella: «Le colgué sin despedirme. Comprensión, cero. ¡Podía pasarme muy bien sin su ternura y soñar noche tras noche con sardinas y Dinamarca!» (Donoso 106), le desagrada, porque no solo no lo entiende, sino que la encuentra cognitivamente limitada. O también al manifestar su indignación con Felipe: «iEste acto demostraba la verdad de la terrible frasecita! Con el índice toque la superficie del cuadro más próximo: mierda azulina» (Donoso 149). A esto se añade la profundidad en la construcción del pasado del personaje que, en el caso del film, se elide:

No dejaba de sentir en el trato de mis colegas cierto ingrediente de envidia por este perfeccionismo que me caracteriza: es fruto de más de dos años de estudios de Derecho, que me vi en la necesidad de suspender a raíz de la muerte de mis padres en un accidente de micro en la cordillera, en viaje de paseo a Mendoza y para comer bifes baratos y comprar suéters. Después, la experiencia me ha hecho confirmar lo que decía Larco: que la envidia es un tributo de la mediocridad al genio. Ahora tengo distancia suficiente para darme cuenta de que las chocarreras bromas de oficina no eran más que una forma de admiración, en realidad, un halago (Donoso 106).

Estos rasgos no solo dan relieve al personaje, sino que, también, evidencian su vanidad. El filme relativiza esto mostrando un personaje menos agresivo, menos indiferente y menos calculador. La escena de la violación a Hildita es mitigada en el film; Marcos parece realmente quererla y se preocupa por Felipe, a pesar del engaño del anciano al no haber arreglado el techo y haber pintado todo de azul, cuando los ancianos de la CPLDDPAN lo obligan a firmar la cesión de las obras.

El correlato real del personaje Larco es Jorge Larco (1897 - 1963) quien fue un pintor y escenografista argentino, que estuvo casado con María Luisa Bombal, pese a ser homosexual. En 1938, fue premiado en el Salón de Viña del Mar. Uno de sus alumnos fue el pintor Marcos Tiglio (1903 - 1976). Quizás estos datos resulten una mera coincidencia de la onomástica, pero son indicios.

Resulta sugerente que en el texto literario Larco no posee nombre; no es así en el filme, donde Marcos encuentra los siguientes datos en la biblioteca: «Gustavo Alfonso Larco (1917- 1963) pintor chileno», todo ello en un libro titulado La peinture latinoamericana des années 1930 - 1950; paralelo curioso si se considera el libro de Jorge Larco La pintura española de los siglos XIX y XX (1947).

Lo tangencial para Marcos es la institucionalización de la palabra «brillante» para referirse al artista; desde ese momento Marcos cambiará su paradigma pictórico en el que solo 
apreciaba las obras de Leonardo, Michelangelo o Rembrandt, para comenzar a apreciar el aporte vanguardista y la atmósfera lúgubre de las pinturas de Larco.

La cromática gris de la pintura de Larco es representada en el filme y también si se piensa en la vida de Marcos. «Naturaleza muerta con cachimba» es presentada a través de una écfrasis nocional (Pimentel 207) en la que se perciben los rasgos vanguardistas de la pintura de la obra:

Me detuve ante NATURALEZA MUERTA CON CACHIMBA: era el resumen de esta casa y por extensión de todo Cartagena, aunque nada fuera una representación real de nada. La guitarra más parecía una sierra, la botella estaba ladeada, unas cuantas letras de periódico magnificadas eran proyecciones de las gafas, la cachimba era como de plasticina, y a la derecha, arriba, había una ventana abierta sobre una usina que colmaba el cielo sin aire con sus chimeneas estilizadas..., no era aire respirable: era pardo, gris, negruzco, ahogante como el resto del espacio plástico, más denso que los objetos que lo ocupaban, que el guante de mujer, que la botella, que la cachimba, relacionados entre sí pero independientes de una perspectiva real. ¿Eran importantes estas relaciones o eran un juego que no debía atraer la atención de una persona seria? ¿O era, en verdad, una mierda el arte...? ¿Cómo iba a ser una mierda si la realidad artificial de este cuadro tenía fuerza para absorber la realidad de toda esta habitación e incorporarla, y a mí, como uno de sus tantos trastos? ¿Cómo explicarme esta dependencia, mi atención conquistada, mis cánones de belleza

— ¿era belleza? - anulados por este cuadro cuya fuerza me retenía? (Donoso 125).

A partir de ese momento, somos espectadores del correlato entre la obra plástica y la vida del héroe, quien ha sucumbido ante el gris de la ciudad. Esta tonalidad se corporiza en la película a través de la mirada de Marcos, quien comienza a ver su vida a partir de la pincelada del artista, convirtiéndolo en un excéntrico e incomprendido.

En palabras de Georges Didi-Huberman ( 35 y ss), cuando estamos frente a una imagen la apertura es doble: se abre la imagen y se abre el cuerpo de quien mira, es decir, se trasciende lo visible. Las imágenes son potencia y ejercen un poder tanto sobre los cuerpos como los espíritus, y este poder se ejerce durante un tiempo, trascendiendo del mismo, adquiriendo especial importancia el anacronismo:

[...] las imágenes, desde luego, tienen una historia; pero lo que ellas son, su movimiento propio, su poder específico, no aparece en la historia más que como un síntoma —un malestar-, una desmentida más o menos violenta, una suspensión. Por el contrario, sobre todo quiero decir que la imagen es "atemporal", "absoluta", "eterna", que escapa, por esencia, a la historicidad. Al contrario, quiero afirmar que su temporalidad no será reconocida como tal en tanto el elemento histórico que la produce no se vea dialectizado por el elemento anacrónico que la atraviesa (Didi Huberman 48-49).

La pintura de Larco es atemporal y Marcos logra abrir la imagen a través del «no-saber», se despoja de su conocimiento a priori, pues es un obstáculo para el universo de Larco. Por ello, el conocimiento de la obra de Larco conlleva un conocimiento de sí mismo, la obra pue- 
de ser conocida únicamente si el «yo» llega a su ipséité3. Marcos, a través de la apertura de la pintura, reconoce su «verdadero yo».

Para el héroe, la mirada es un cambio de paradigma estético de lo clásico a lo vanguardista. La incomprensión de la pintura de Larco por la sociedad evidencia la crisis de un sistema de valores donde no se pueden proponer ideas diferentes.

El cuadro en sí representa la complejidad de sentido que adquiere para el espectador y también la crisis del sentido único que dejaron en evidencia vanguardias como el cubismo, así:

Esta tematización del "mirar con atención" se convierte en la clave y al mismo tiempo en su antítesis. La dificultad de la percepción y su fragmentación esclarecerán finalmente nuestra manera de ver (Stoichita 19).

Frente a ello, es necesario reparar en la «cachimba» por tres razones. En primer lugar, es el objeto del cuadro y es el hipertexto de la obra de René Magritte, artista que quería «crear algo más real que la propia realidad» (Gombrich 457), poniendo en crisis la relación entre las imágenes y su representación. En segundo lugar, la «cachimba-objeto», en la casa-museo, era propiedad de Felipe, quien fumaba en ella, pero que posteriormente pasa a ser propiedad de Marcos una vez que ha finalizado su transformación y se ha convertido en un artista... o en la representación de un artista, se preguntaría Magritte. En última instancia, es preciso detenerse en el porqué del título del film, en tanto que rescata la cachimba en un juego de metonimia, debido a que este objeto fantástico faculta la transformación de Marcos en Larco.

Este planteamiento nos lleva a la idea y fuerza de esta lectura. En la nouvelle podemos constatar que Larco se autoexilia en Cartagena y crea a Felipe como forma de preservar su pensamiento y obra. No obstante, en el filme tal afirmación sería arriesgada. Consideramos que la película deja suficientes espacios vacíos como para pensar que Felipe Sanhueza era o no era Larco. Esto, debido a que en ningún momento se enuncia de forma literal y, además, a la presencia y sentido de la cachimba. Felipe fuma en ella y afirma que es ella la verdadera inspiración del artista, rasgo que queda en evidencia en el desenlace de ambos discursos, pues se presenta a nuestro héroe fumando en ella.

Marcos Ruiz Gallardo se hunde en el universo de Larco y, a partir de ese momento, su mirada comienza a ser tangencial: su pulsión sexual es anestesiada por este universo artístico y comienza a mirar la vida con los ojos del arte, el protagonista queda atrapado en el cuadro que tanto lo obsesiona. Victor Stoichita lo plantea como:

[...] la tematización de la mirada en el interior del campo de la imagen contiene siempre una ilusión dirigida al espectador del cuadro. Descifrar dicha ilusión significa acercarnos a la concepción de la imagen e incluso llegar a captar la idea del cuadro (Stoichita 16).

Concepto en francés que se puede homologar a "ipseidad" en referencia a la idea de "sí mismo". 
Esta idea implica que cuando Marcos ingresa al espacio heterotópico del museo Larco y observa «Naturaleza muerta con cachimba», comienza una tarea de exégesis donde no solo se encuentra ante la pintura, sino también ante el pintor Larco y su vida, para así poder ingresar a la imagen.

La idea del cuadro lo apresa y comienza a yuxtaponer la pintura a la realidad y su propia vida a la vida de Larco: velas como un fresco, se sienta en el mismo lugar que el artista y comienza a imaginar cómo habría percibido la realidad Larco. El cine potencia esta transformación a través de los puntos de la cámara que emulan las olas fotografías que Felipe le mostró de Larco y la baronesa. A partir de ahora, el mismo Ruiz Gallardo tendrá visiones en sepia.

Luego de descubrir el ardid de Felipe, se instala en Cartagena con la pipa que heredó del anciano cuando era trasladado al hospital: «— ¡Que aprendan estos hijos de puta! — y al reírse se le cayó la cachimba de la boca y su cabeza se volcó sobre la almohada» (Donoso 150), y se dedica a quitar la pintura azul y, de vez en cuando, vender alguna obra. Nadie sospecha de él, pues nadie le sustituyó valor a las pinturas de Larco.

Lo anterior permite preguntarse si es más importante el pintor Larco o la pervivencia que personajes como Felipe (Larco o no Larco) o Marcos le pueden brindar a la obra del artista. Así como Magritte pone en crisis un sistema, Donoso y Caiozzi critican la institucionalidad del mundo del arte y también la identidad del artista, razón que explicaría la elección del título del filme por parte del realizador.

\section{Hilda y Marcel}

La reflexión que posibilita Sánchez Noriega a partir de la reflexión entre los elementos que se cambian, agregan o sustituyen, resulta interesante al pensar en el sentido de lo transmitido. Hilda Botto Gamboa tiene 33 años en el texto literario, es reprimida, contenida y fiel a la tradición. También, como advierte Gatti Riccardi (33), la diferencia respecto de su personaje fílmico guarda relación con su aspecto físico, pasando de lo endeble a la corpulencia en el filme.

Es pertinente detenerse en este rasgo, puesto que fuera de lo estético, este vigor presentado en la película es un correlato de la fuerza interior. Mientras que la pareja se encuentra en la casa/ museo por primera vez, apreciamos que Hilda no es capaz de leer un año como una cifra de cuatro dígitos. En el texto literario, Ruiz dice que: «La Hildita estudió un año de periodismo antes que su ortografía la delatara como irremediablemente disléxica» (Donoso 104).

A pesar de ello, Hilda es quien salva a Marcos cuando lo están agrediendo el día de la in- auguración del «Museo Larco». Sumado a lo anterior, en el filme adquiere mayor valor en la vida del protagonista; él parece quererla y la noche estrellada en que le entrega el anillo ambos viven una experiencia mágica con las luciérnagas. Escena relevante, donde solo están enfocados ambos protagonistas y el universo queda suspendido. 
Hilda es quien posibilita el conocimiento de Larco. En su afán por rehuir de los encuentros a solas con su novio recorren los alrededores de Cartagena, donde descubren las ruinas del «Museo Larco».

Un último aspecto es la relación que se puede establecer entre Hilda y la baronesa Elsa von Freytag-Loringhoven (1874 - 1927), musa de Larco y artista dadá. En el desenlace de la historia vemos a Hilda con el kimono naranja, es la musa de Marcos (ahora convertido en Larco). Hildita, de 33 años, cual Cristo, renace transfigurada en la baronesa; en lo que la baronesa representaba para Larco, por ello, será quien finalmente acompañe a Marcos en el cambio pictórico que hizo Felipe en «Naturaleza muerta con cachimba»:

[...] todo había cambiado. Un mundo distinto ocupaba ese espacio ahora. En colores profundos, como de viejas joyas, amatistas, zafiros, granates, una mano diestrísima había pintado un minucioso paisaje de rocas y de mar que reconocí como el Suspiro, y sobre ese paisaje, de medio perfil como en los retratos italianos del Renacimiento, en traje de princesa recamado de pedrería, la Hildita, bella como sólo los ojos de ese hombre la vieron, se volvía hacia mí. Al lado derecho y también de medio perfil y con una gallardía que le hacía honor al apellido de mi madre, estaba yo, de jubón de terciopelo color guinda, vuelto hacia ella. Entrelazábamos nuestros dedos sobre el reborde inferior que imitaba madera, en que se leía: EL CABALLERO MARCOS RUIZ GALLARDO Y SU DAMA, firmado Larco en letras azulinas: la pintura de la firma estaba fresca. Nos bañaba una luz cálida, dorada, la luz de la belleza que bañaba también la mesa de hule, y la habitación, y la casa (Donoso 151-152).

El personaje de Marcel constituye una añadidura en el film. Su importancia radica en su tanguería y la representación de la pasión. Este personaje constantemente le está señalando a Marcos la importancia del amor y la pasión, lo cual se representa a través del baile y del amor.

Una vez que Marcos ha descubierto a Larco y obtiene una recepción positiva de la CPLDDPAN se desenvuelve con soltura en la pista de baile, pues ha descubierto la pasión que el universo de Larco es capaz de producirle.

Durante el cumpleaños de Marcel, este le entrega un regalo: un anillo de diamantes falso y le hace apreciar su belleza a pesar de su falsedad, para luego decirle que en la vida lo más importante es el amor y que se debe alimentar. Este objeto es decisivo, pues está hermanado a la cachimba: ¿qué es más importante: que un anillo sea realmente bello o que sea un diamante real?

Como acápite a lo mencionado, es preciso relevar la elección de la música que se hace en el filme, pues estos son sonidos latinoamericanos como vals, tango y boleros que otorgan un sello íntimo y local a la historia, en concordancia con el juego entre Jorge Larco y el Larco donosiano. 


\section{Humor}

Fue necesario enunciar todo lo anterior para retomar nuestra propuesta: ¿Marcos es un reflejo especular del pintor Larco? Para Michel Foucault ( 65 y ss) el espejo es una heterotopía y una simbiosis entre estar y no estar. Larco existe gracias al artilugio de Felipe y, posteriormente, gracias a Marcos; en este sentido, Felipe es un gestor de memoria del universo de Larco que cede su sapiencia a Marcos para recuperar y perpetuar el universo larquiano. Sin embargo, el espejo no es solo un reflejo, sino que se produce una fusión entre ambos personajes:

El espejo no tiene solamente por función reflejar una imagen; el alma, convirtiéndose en un perfecto espejo, participa de la imagen y por esta participación sufre una transformación. Existe pues una configuración entre el sujeto contemplado y el espejo que lo contempla. El alma acaba por participar de la belleza misma a la cual ella se abre (Chevalier y Gheerbrant 477).

En este marco, es preciso indicar que, si bien en el desenlace Marcos transmuta en Larco, lo hace de un modo humorístico. Su musa, Hildita, es la inversión paródica de la baronesa dadá que «se lucía por los bulevares de París con su melena adornada con latas de sardina para escandalizar a los burgueses» (Donoso 102). La musa de Marcos es tradicionalista y la atemorizan los juicios que las personas puedan tener de ella, un ejemplo de esto es la conclusión a la que llega Hildita respecto del cambio en la pintura: «-Claro que se dan cuenta de que yo, en jamás de los jamases, me pondría un vestido tan escotado» (Donoso 106).

El círculo de personas relacionadas al mundo del arte demuestra prejuicio y vanidad. Si ninguna «autoridad» ha valorado al pintor Larco, son incapaces de apreciar su obra o como menciona Artemio en el film «esto es arte de la miseria»:

¡Los cuadros de Larco, ni regalados! No podían valer nada esos adefesios que daban risa. Todos estuvieron de acuerdo en que no eran del tipo de trabajo que nuestra institución debía propiciar y proteger, sin que nadie se aviniera a explicar en qué podía consistir la protección de un grupo tan desprovisto de poder como el nuestro. ¡Qué justificada esa anarquía de cubos, me exigieron, esos trapos pegados, ese revoltijo de letras y números! ¡Todo era horrible! (Donoso 130).

Asimismo, se manifiesta en la confrontación entre el mundo del arte y de las apariencias a través de personajes como Artemio, la bibliotecaria y Perico Retamal, quienes quieren aparentar o tener un beneficio económico a partir del descubrimiento del «Museo Larco». Estamos en presencia de la «succión del absurdo» (Sypher 15), por medio de situaciones carentes de heroísmo, al borde del patetismo. Es el caso de Antoniette quien, durante la inauguración del Museo, es pisada y exclama un insulto típicamente chileno.

El humor se presenta a través de las diversas vidas fragmentarias de los personajes convocados en el texto literario y fílmico. Marcos consigue que publiquen una nota en un diario, pero en la sección «Espectáculos» (Donoso 104). En otras palabras, evidenciamos que el mundo del arte no es lo que debiese ser y nos reímos para no llorar. 
Marcos busca eludir su realidad cuando conoce el universo de Larco y para ello construye su «ventana utópica» (Bloch 193). Un paisaje a construir, una forma de salvación ante el extravío y extrañamiento del mundo: «En medio de la miseria, de la crueldad, de la dureza, de la trivialidad, proyectando o conformando, se abren amplias ventanas hacia el futuro llenas de luz» (Bloch 126). No obstante, este proyecto vuelca hacia el absurdo: no es pintor, ni mucho menos es Larco; tampoco aprecia a su novia. Solo la presencia de Felipe y Marcel hacen que el protagonista comience a «ver» a Hilda: «—Dele saludos a su novia. / —No tengo novia. / — ¿Cómo no? ¿Y esa chiquilla tan interesante que vino con usted la primera vez...?» (Donoso 135). Anterior a ello, Ruiz veía su relación como una mutua cooperación para librar sus soledades:

Sí. Tonta. Y también fea. Pero callé. ¿Qué otra cosa podía hacerme a estas alturas? ¿Qué me había hecho meterme con ella sino mi certeza de que por su insignificancia no podía darse el lujo de rechazarme? ¿Qué nos había mantenido juntos sino el miedo de que si nos separábamos quedaríamos solos para siempre? (Donoso 113).

El humor presente es próximo al llanto, la CPLDDPAN no está realmente interesada en el arte ni en escuchar nuevas propuestas. Felipe es un personaje ruinoso, cercano a lo escatológico y Marcos se encuentra sumido en un tedium vitae hasta que el universo de Larco le permite construir una realidad alternativa, donde él puede ser Larco e Hilda su musa.

\section{Conclusiones}

Para finalizar esta lectura comparatista, es preciso reiterar que el cine utiliza como base la percepción visual y auditiva, mientras la literatura utiliza el lenguaje verbal como subterfugio para la reflexión abstracta.

El arte se refleja de manera distinta en ambos soportes: el discurso literario tiene la posibilidad de écfrasis y, en general, de la descripción que el discurso fílmico no posee; no obstante, hace uso del espacio fílmico y de la mirada de Marcos para poder representar el arte.

La pintura es entendida como mimesis, como reflejo de la realidad: la vida de Ruiz es tan grisácea como una naturaleza muerta.

El descubrimiento del universo de Larco se presenta a través de la apertura del cuadro en el que se suprime la distancia entre el que observa y lo observado: «La imagen está, pues, abiertamente sobredeterminada respecto del tiempo. Eso implica reconocer el principio funcional de esta sobredeterminación dentro de una cierta dinámica de la memoria» (Didi-Huberman 42). La imagen, como Larco, posibilita que su obra se perpetúe; al abrirse la imagen puede contener todos los tiempos y todos los espacios, es decir, el tiempo y el espacio de todos lo que la han mirado, la miran y la mirarán.

Se genera un discurso ambiguo y dicotómico, en el que se pone en crisis la importancia de conceptos como: la autoría y la realidad. Esta es una vital discusión en relación con el cine, 
puesto que, así como no es relevante hablar de «fidelidad» en una transposición, pareciera que tampoco lo es en el caso de la identidad de Larco, como sí sería su obra y arte.

La cachimba es un objeto mágico, totémico, que pasa de Larco a Felipe, hasta llegar a Marcos. Así, el protagonista finaliza suplantando la vida de Larco, no por lo que ha averiguado de él, sino por su intuición e imaginación sobre cómo vivía y qué pensaba el artista, pues la «metamorfosis existencial» lo imbuye de su mundo (o de lo que Ruiz cree que es su mundo) y comienza a entender por qué Felipe decía: «Es la vida lo que tiene que ser una obra de arte, decía: el arte es una mierda» (Donoso 120).

Marcos es una naturaleza muerta con cachimba, es un outsider, un perdedor, un habitante de un siglo anterior, hasta que descubre al pintor quien es su cachimba. Evidentemente, Ruiz no es un artista, es el reflejo especular de Larco logrado a través de la posesión de la pipa. Es la posibilidad de perpetuar a un artista olvidado y la oportunidad personal de encontrarle sentido a su existencia.

Por razones de extensión, esta breve lectura ha dejado fuera temas interesantes como la relación entre Donoso y Couve. Recordemos que tanto Larco como Camondo, el protagonista de La comedia del arte (1995), deciden autoexiliarse y radicarse en un balneario decadente como es Cartagena. Por lo mismo, en ambas novelas se tematiza la mirada y los paisajes marinos, poniendo en crisis la representación de la realidad (Schoennenbeck 252); idea clave en esta lectura donde tienen cabida la fantasía y la crisis desde una perspectiva única.

Estudiar a fondo el vocabulario utilizado, la música y la relación con el cuerpo es una lectura pendiente. Puesto que al igual que los encuadres y los puntos de cámara utilizados en el film, en relación con la «metamorfosis existencial» de Marcos, este vocabulario sería un aporte enriquecedor para comprender el proceso del protagonista, al igual que la presencia iterativa del vagabundo en la película. O la relación con la violencia encarnada en personajes como Artemio, los guardias y agentes de seguridad, un guiño probable a los pasajes más oscuros de la historia nacional.

Pareciera ser que estudiar una comedia tiene menos de concluyente, pues entraña relaciones confusas, arriesgadas y pendientes.

\section{Referencias}

Biénzobas, Pamela. "Donoso y el cine". Rocinante, vol 12, 1999, pág. 15. Web 7 de agosto de 2020 http:// www.letras.mysite.com/donoso41.htm

Bloch, Ernst. El principio de la esperanza (vol. 1 y 2) (Trad. F. González). Madrid, Trotta, 2004. 
Cachimba. Dir. Silvio Caiozzi. Andrea Films, 2004. DVD.

Cid Hidalgo, Juan. "Larco: museo, memoria, déjà vu". Literatura: Teoría, Historia, Crítica, vol 21(1), 2019, págs. 225-252. doi: https://dx.doi.org/10.15446/lthc.v21n1.74817

Chevalier, Jean y Gheerbrant, Alan. Diccionario de los símbolos (Trad. M. Silvar y A. Rodríguez). Barcelona, Herder Editorial, 1986.

Didi-Huberman, Georges. Ante el tiempo. (Trad. A. Oviedo). Buenos Aires, Adriana Hidalgo Editora, 2018.

Donoso, José. Átomo verde número cinco. 1973. Recuperado de https://bit.ly/2Rw7xLZ

Taratuta. Naturaleza muerta con cachimba. México, Grijalbo, 1990.

Fernández, Mariano. “Cachimba”, la comedia que cautivó a Silvio Caiozzi [Entrevista]. Web 10 de agosto de 2020 de http://www.cachimba.cl/downloadEntrev.pdf

Foucault, Michel. "Espacios diferentes". El cuerpo utópico. Las heterotopías. (Trad. V. Goldstein). Buenos Aires, Nueva Visión, 2010, págs. 63-81.

Gatti Riccardi, Giuseppe. "De la literatura al cine: isotopías fílmicas en Naturaleza muerta con Cachimba. La transposición fílmica de la nouvelle donosiana". Guaraguo, vol 42, 2013, págs. 29-50.

Gombrich, Ernst Hans Josef. Historia del arte (Trad. R. Santos). Madrid, Phaidon, 2010.

Iser, Wolfang. El acto de leer: teoría del efecto estético (Trad. M. Barbeito). Madrid, Taurus, 1987.

Pimentel, Luz Aurora. "Écfrasis y lecturas iconotextuales”. Poligrafias, vol 4, 2003, págs. 205-215. Recuperado de http://www.revistas.unam.mx/index.php/poligrafias/article/ view/31343

Rebolledo, Matías. Transformaciones de la voz narrativa en la transposición de textos literarios al cine: las resistencias de una narración «silenciosa〉 (Tesis de maestría, Universidad de Chile, Santiago de Chile). 2008. Web 5 de agosto de 2020 http://repositorio. uchile.cl/ handle/2250/108503

Sánchez Noriega, José Luis. De la literatura al cine. Teoría y análisis de la adaptación. Barcelona, Paidós, 2000.

Sypher, Wylie. Los significados de la comedia (Trad. L. Vaisman). Santiago, Editorial Montacerdos, 2015. 
Schoennenbeck, Sebastián. "De la luz a las sombras: Los jardines de José Donoso y Adolfo Couve". Universum (Talca), vol 33, 2018, págs. 240-259. doi: https://dx.doi.org/10.4067/ S0718- 23762018000100240

Stoichita, Victor. Ver y no ver (Trad. A. Codderch). Madrid, Siruela, 2005.

Wolf, Sergio. Cine / Literatura. Ritos de pasaje. Buenos Aires, Paidós, 2001. 